\title{
Correction to: Organising the module category
}

\section{Flávio U. Coelho ${ }^{1}$}

Published online: 12 October 2021

(C) Instituto de Matemática e Estatística da Universidade de São Paulo 2021

\section{Correction to: São Paulo Journal of Mathematical Sciences https://doi.org/10.1007/s40863-021-00241-4}

In this article Ref. [9] was incorrect, and was updated to read "Graduate Texts in Mathematics" instead of "Graduate Studies of Mathematics."

Publisher's Note Springer Nature remains neutral with regard to jurisdictional claims in published maps and institutional affiliations.

The original article can be found online at https://doi.org/10.1007/s40863-021-00241-4.

\section{Flávio U. Coelho}

fucoelho@ime.usp.br

1 Institute of Mathematics and Statistics of the University of São Paulo, São Paulo, Brazil 